\title{
A FORMAÇÃO CONTINUADA EM TUTORIA A PARTIR DA INTERAÇÃO NO AMBIENTE VIRTUAL
}

\author{
THE CONTINUING TRAINING IN TUTORING \\ FROM THE VIRTUAL ENVIRONMENT \\ INTERACTION
}

Igor Adolfo Assaf Mendes ${ }^{1}$, Jacqueline de Castro Laranjo ${ }^{2}$, Francys Silva Araújo ${ }^{3}$

${ }^{1}$ Graduado em

Ciências Sociais,

Doutorando em Educação.

igoriscoe@yahoo.com.br

${ }^{2}$ Graduada em Ciências

Biológicas, Doutoranda

em Educação. jacqueline.

laranjo@hotmail.com

${ }^{3}$ Licenciada em

Letras, Designer

Instrucional no GIZ/

Prograd. francysfale@

gmail.com

\section{RESUMO}

Este artigo relata a formação continuada da Tutoria na experiência de educação a distância (EaD) implementada na Universidade Federal de Minas Gerais (UFMG) por meio do GIZ/Prograd. No contexto do Reuni, o GIZ implementou o Curso Formação em Docência do Ensino Superior. Ofertado a mestrandos e doutorandos da UFMG, o curso dispõe de uma equipe composta, em sua maioria, por pós-graduandos em Educação, além de funcionários do GIZ. A formação acontece em um espaço de interação virtual - Sala dos Tutores - no qual as estratégias didático-pedagógicas são discutidas antes de serem implementadas. Os desafios em estabelecer uma dinâmica pedagógica eficiente, com base nos aspectos teóricos, metodológicos e tecnológicos da formação, foco desta análise, foram sistematicamente discutidos e desenvolvidos nesse espaço, ao mesmo tempo que ocorria a formação teóricoprática dos sujeitos. Os resultados remetem à reflexão sobre as potencialidades pedagógicas da formação a distância dos sujeitos que atuarão com a Tutoria em EaD.

Palavras-chave: Educação a distância. Tutoria. Formação continuada. Sala de tutores. Docência do ensino superior. 


\section{TUTOR NA EDUCAÇÃO A DISTÂNCIA (EAD) E A FORMAÇÃO PARA TUTORIA}

Data do século XV, na Inglaterra, o aparecimento da figura do tutor, mais especificamente nas universidades de Oxford e Cambridge. Nesse caso, o conceito de tutor derivado do campo jurídico, no qual uma pessoa é designada para exercer a função legal de tutela de alguém que não tenha condições de se manter sozinha. Geralmente crianças menores de idade ou pessoas com algum tipo de necessidade especial, cujo tutor desempenharia a tutela protegendo o menor e administrando seus bens até que esse alcançasse a maioridade ou, caso não tenha condições de se manter sozinho, ao longo de sua vida (PRETI, 2003).

Nessa mesma época, adaptado ao setor acadêmico, o tutor tinha por função auxiliar estudantes não somente nas questões acadêmicas, como também zelar pela manutenção de um comportamento social adequado às regras da sociedade vigente. Outra diferença marcante em relação ao campo jurídico é que, no âmbito educativo, o tutor também permanecia sob a orientação de um professor titular, que acompanhava o desenvolvimento das atividades da Tutoria (PRETI, 2003).

Somente a partir do século XIX, a Tutoria se institucionaliza nas universidades como parte integrante do quadro docente. Ela é implementada em universidades que trabalham com a modalidade a distância, como a Open University, na Inglaterra; a UNED, na Espanha; a Anadolu University, da Turquia; a 
Universidade da África do Sul; a Indira Gandhi National Open Univesity, da Índia, entre outras (PRETI, 2003).

Ainda segundo o autor referido acima, nessas instituições, a Tutoria deveria desempenhar, principalmente, as seguintes atividades:

- ver o que o estudante realizou por ele mesmo numa determinada disciplina, assegurando-se que compreendeu e pode argumentar o que escreveu;

- clarear as dúvidas, corrigir e ampliar a compreensão e informação do estudante, mediante o diálogo e a realização de exercícios práticos;

- animar o estudante a fazer outras leituras e a realizar trabalhos práticos que lhe facilite a compreensão dos conteúdos teóricos;

- $\quad$ assessorar sobre os conteúdos e os enfoques em que o estudante deverá trabalhar durante a semana e que deverão ser apresentados na sessão Tutorial seguinte;

- realizar função avaliativa formativa permanente, comprovando os avanços do estudante e suas dificuldades durante o processo de aprendizagem (PRETI, 2003 p. 5). 
Ao longo do tempo, modelos de Tutoria foram sendo experimentados, validados por diferentes instituições, de acordo com os seus objetivos educacionais. Alguns privilegiaram o trabalho voltado à orientação de métodos de estudo, outros, um trabalho da Tutoria mais próximo da docência, atribuindo ao tutor a função de não apenas ensinar-aprender, como também de disponibilizar materiais didáticos aos estudantes. Há também modelos híbridos, nos quais ambas as funções (orientador de estudo e docência) se mesclavam (PRETI, 2003).

Assim, é necessário diferenciar as funções docentes que são desempenhadas na educação a distância (EaD) daquelas que são conhecidas e determinadas para educação presencial, dadas as características peculiares de cada uma, principalmente, no que se refere à função do tutor, figura central para o sucesso e a qualidade em uma formação a distância. O tutor é a referência da instituição junto ao estudante, orientando-o, ensinando-o e apoiando-o durante o desenvolvimento do curso, sendo, por isso mesmo, de suma importância que recebam uma formação específica para o desempenho dessa função. García Aretio (1994) destaca que não cabem improvisação e amadorismo no exercício da Tutoria, sob o risco de, com isso, a qualidade do curso ficar comprometida.

Ou, no dizer de lanh (2002), a estrela da EaD ficaria disforme e sem brilho. A EaD é representada por esse autor como uma estrela de cinco pontas perfeitas, que representa em cada uma das pontas as figuras do aluno (1), do tutor (2), do professor (3), e dos componentes: material didático (4) e avaliação (5). Para que o processo educativo alcance seus objetivos e 
seja um sucesso, as cinco pontas precisam estar integradas e funcionando de maneira uniforme, caso contrário, não subsistirá e não terá força para brilhar.

Os referenciais de qualidade para a EaD no Brasil (BRASIL, 2007b, p. 21) coadunam com essa assertiva, destacando que os tutores (um das pontas da estrela) desempenham "papel de fundamental importância no processo educacional de cursos superiores a distância e compõem quadro diferenciado, no interior das instituições", tendo em vista a atuação e contribuição desses atores nos processos de ensino e aprendizagem, assim como no acompanhamento das tarefas e avaliações que os estudantes desenvolvem ao longo do curso.

Como participante vital da atividade pedagógica de um curso a distância, o tutor realiza a mediação junto aos estudantes, quer seja no apoio presencial, quer seja no virtual. Neste artigo, o foco ocorre no tutor a distância, que atua via ambiente virtual de aprendizagem, junto aos estudantes que se encontram tanto espacial quanto temporalmente distantes. Relata-se, aqui, a experiência de formação da Tutoria em um curso de curta duração cujo foco é a formação para a docência no ensino superior.

Cabe destacar que, além do contato com o estudante, o tutor se vale também da rica troca de conhecimentos e experiências com outros tutores e professores do curso. Ou, ainda, descobre sozinho quais são os limites e as potencialidades do uso da tecnologia e mediação na $\mathrm{EaD}$, bem como aprende a otimizar a comunicação com os estudantes por meio dessa tecnologia (MOORE; KEARSLEY, 2008). 
Mill (2006) ressalta que o desenvolvimento das atividades docentes na $\mathrm{EaD}$ se caracteriza por ser dividido entre os integrantes de uma equipe colaborativa, configurando um trabalho chamado por ele de polidocência. Em sua pesquisa, diversos teletrabalhadores docentes evidenciaram a importância das trocas de saberes nos ambientes virtuais para se evitar o sentimento de solidão. Para esse autor, as tecnologias de informação e comunicação, apesar de possibilitarem, não estimulam a comunicação, por isso, esse intercâmbio de conhecimento depende, em grande parte, da iniciativa do grupo ou mesmo de cada trabalhador.

Conforme apontado por Moore e Kearskey (2008), há pouca experiência entre os docentes atuais-formados principalmente na educação presencial - para atuar na docência a distância ou ainda usando a tecnologia. Nesse sentido, é importante para a formação do tutor que atuará em ambientes virtuais de aprendizagem pautar-se em ferramentas capazes de desenvolver competências e habilidades necessárias para a realização da mediação do conteúdo e o desenvolvimento da interação.

Se considerarmos uma abordagem construtivista de educação, a aprendizagem na EaD ocorre na interação entre sujeitos (professores, tutores e estudantes) e entre estes com os objetos (conteúdo do curso). Neste caso, o tutor, ao propor situações desafiadoras para o estudante, de forma a fazê-lo repensar a realidade a sua volta e buscar novas soluções para os problemas apresentados, desperta o interesse intrínseco por sua própria ação (MIZUKAMI, 1985). Dessa forma, em uma 
atividade de formação de tutores para atuar a distância, devese privilegiar atividades que estejam diretamente relacionadas a sua prática cotidiana e, para isso, utilizar dados levantados a partir de sua própria rotina.

\begin{abstract}
Quer-se aqui enfatizar a interação como elemento catalisador para a construção do conhecimento. Não uma interação determinística, de objetivos fechados, com desenrolar previsto por antecedência. Mas uma relação que valoriza o diálogo, a negociação, a cooperação, enfim, a transformação mútua. (PRIMO, 2001, p.13)
\end{abstract}

Nessa perspectiva de cooperação mútua, o tutor deve ser incentivado a desempenhar o papel de "provocador", suscitando questões que possam desequilibrar as certezas do estudante, motivando a discussão de temas de interesse para sua prática, promovendo um ambiente de cooperação, negociação e construção coletiva do conhecimento. Por isso, uma formação para capacitar o tutor para atuar em cursos a distância deve levar em consideração aspectos como o conhecimento sobre as características da EaD com base em pressupostos teóricos, ao mesmo tempo que apresenta situações práticas para utilização das ferramentas tecnológicas empregadas nesse modelo de ensino. Além disso, uma capacitação realmente eficaz deve prover o tutor de ferramentas e ações práticas da Tutoria, atualizando-o acerca das diferentes formas de inserção das tecnologias da informação e comunicação aplicadas ao ensino (GARCÍA ARETIO, 1994). 


\section{A SALA DE TUTORES: PARTE DE UM AMBIENTE VIRTUAL}

O Curso Formação em Docência do Ensino Superior é realizado desde 2008 pelo GIZ. Criado ainda como um núcleo, hoje o GIZ é uma Diretoria de Inovação e Metodologias de Ensino vinculada à Pró-Reitoria de Graduação da UFMG (Prograd) e tem como finalidade o aprimoramento das metodologias a partir do uso de novas tecnologias, incentivando a formação de uma rede de desenvolvimento de práticas de ensino superior. Entre as muitas experiências de formação de (futuros) professores, pós-graduandos de diversas áreas do conhecimento, o GIZ tem mantido uma contribuição substancial à UFMG, principalmente no que diz respeito ao uso de novas tecnologias como mediadoras da relação ensino-aprendizagem.

O interesse pela educação a distância somado às facilidades provenientes da tecnologia digital possibilitaram avanços pedagógicos e logísticos (BEZERRA; CARVALHO, 2011) que se tornaram base para o que foi chamado de Ambiente Virtual (AV). Mais do que uma sala de aula, o AV permite a integração de aspectos das famosas Redes Sociais: como perfis, fotos dos usuários e sistema de troca de mensagens; além de características de sala de aula: com discussões do conteúdo entre os estudantes e apresentação de trabalhos; e também: uma biblioteca virtual onde se tem acesso a todo o material necessário para o desenvolvimento dos estudos e trabalhos. Segundo os autores Bezerra e Carvalho (2011), o AV viabilizou:

“[...] a transmissão rápida de informações a qualquer momento para toda a parte, genuínas possibilidades para a aprendizagem autônoma, 


\begin{abstract}
maior interatividade, mais orientação para os/as estudantes, maior individualização, melhor qualidade dos programas e maior eficácia da aprendizagem." (BEZERRA; CARVALHO, 2011, sem página)
\end{abstract}

Dessa forma, o GIZ, por intermédio de sua equipe multidisciplinar responsável pela oferta do curso de formação de docentes, organizou o AV como um "local" de trabalho mergulhado em todas as possibilidades ofertadas pela tecnologia de educação a distância. Nessa nova perspectiva de relação ensino-aprendizagem, não só no $\mathrm{GIZ}$, como em todos os cursos que passaram a utilizar o modelo de ensino a distância, emergiu a figura do tutor, que é distinta do professor, com atribuições diferenciadas, mais próximo do aluno ou cursista, seja em sala de aula, seja no AV. O papel do tutor na organização das atividades presenciais e on-line para o sistemas de $\mathrm{EaD}$ tornou-se destaque em outros trabalhos ${ }^{1}$ sugerindo que seu papel é imprescindível na comunicação com a turma, pois ele media a relação homem-máquina, reduzindo a possível frieza proveniente da tela e dos circuitos de computadores.

Apesar de estarmos em tempos digitais, nos quais a figura do professor sofre alterações quanto às relações estabelecidas com os alunos, há necessidade de se construir uma forma de trabalho para ambos os lados, pautada na criatividade e na interatividade. No caso dos cursistas do GIZ, o tutor representa essa figura humana que permite uma identificação com o aprendizado.

\footnotetext{
${ }^{1}$ Ver: DUARTE e POLAK, 2007; OLIVEIRA, MILL e RIBEIRO, 2009; e BEZERRA e CARVALHO, 2011.
} 
Como forma de apoiar e orientar os tutores nos períodos entre as reuniões presenciais semanais e para fazer uso mais apropriado do AV, foi criado, no primeiro semestre de 2012, em função do significativo aumento da equipe, a Sala de Tutores. Trata-se de um ambiente virtual que serviria exclusivamente para tratar de assuntos relacionados à Tutoria e ao qual somente os profissionais e bolsistas do GIZ envolvidos na formação dos cursistas teriam acesso.

Diante dessas três novidades - o Ambiente Virtual de Aprendizagem, o Tutor Virtual e a Sala de Tutores -, surgiu uma pequena pesquisa entre os participantes da Tutoria com o intuito de observar as concepções e práticas relacionadas à Sala de Tutores. Os dados que são apresentados a seguir foram levantados entre 14 bolsistas e profissionais que participaram, durante o ano de 2013, e que ainda participam das atividades do GIZ e tiveram contato com a Sala de Tutores. A ideia era captar a percepção da equipe quanto ao próprio trabalho, mas também o papel da Sala de Tutores na organização dele. As informações foram coletadas via questionário autoaplicado e digital - como não? -, além de livre observação. ${ }^{2}$

\section{PERFIL DA TUTORIA: QUEM SÃO OS TUTORES DO}

\section{GIZ}

A equipe de Tutoria do GIZ é composta por graduados em diversas áreas, que estejam vinculados à UFMG via Programa

\footnotetext{
${ }^{2}$ Consistiu na observação do uso da Sala de Tutores pela equipe, como tipos de uso, divulgação de trabalhos, fórum de notícias, meio de comunicação, recados etc.
} 
de Pós-Graduação em Educação - mestrado ou doutorado. Entre 2008 e 2013, integraram também a equipe servidores da Universidade ligados à Prograd e a alguns funcionários. Nem todos os que passaram pela Tutoria tiveram contato com a Sala de Tutores, que não existia nos primeiros anos da formação. $O$ pequeno questionário elaborado para este artigo foi aplicado entre os tutores que participaram das atividades de 2013 - no primeiro e no segundo semestres. Nesta primeira parte, nosso objetivo foi de delinear o perfil da equipe (Tabela 1)

Interessante destacar que, em relação ao vínculo com a Universidade, a Tabela 1 nos revela uma composição de equipe com predominância de bolsistas vinculados ao mestrado, seguidos pelos bolsistas de doutorado. Tal situação se justifica pela Proposta de Adesão da UFMG ao Programa de Apoio ao Plano de Reestruturação e Expansão das Universidades Federais (Reuni), instituído pelo Governo Federal por meio do Decreto 6.096, de 24 de abril de 2007 (BRASIL, 2007a), e enviada pela UFMG ao Ministério da Educação (MEC) naquele ano. O referido programa foi extinto no primeiro semestre de 2014 e teve, entre outras metas, a reordenação das Instituições Federais de Ensino Superior (Ifes), as quais deveriam articular a graduação com a pós-graduação e democratizar o acesso ao ensino, e, a partir de um plano estratégico próprio, apresentar projetos para desenvolver a formação docente de novos professores e alunos de pós-graduação. De acordo com as Diretrizes Gerais do Reuni, publicadas em 2007 (BRASIL, 2007c), com o objetivo de orientar as instituições sobre as suas propostas de adesão ao programa, as universidades também deveriam desenvolver novas práticas pedagógicas e promover o uso de tecnologias que possibilitassem uma renovação do 
Tabela 1 - Descrição do perfil dos tutores

\begin{tabular}{|c|c|c|}
\hline Característica & $\mathrm{N}=14$ Tutores & $\%$ \\
\hline \multicolumn{3}{|l|}{ Vínculo com o GIZ: } \\
\hline Bolsista Doutorado & 5 & 35,7 \\
\hline Bolsista Mestrado & 6 & 42,9 \\
\hline Vinculo profissional & 2 & 14,3 \\
\hline N.S./N.R & 1 & 7,1 \\
\hline \multicolumn{3}{|l|}{ Graduação: } \\
\hline Ciências Sociais & 1 & 7,1 \\
\hline Pedagogia & 8 & 57,1 \\
\hline Geografia & 1 & 7,1 \\
\hline História & 2 & 14,3 \\
\hline Educação Física & 1 & 7,1 \\
\hline N.S./N.R & 1 & 7,1 \\
\hline \multicolumn{3}{|c|}{ Tempo de trabalho como tutor no GIZ: } \\
\hline 1 semestre & 4 & 28,6 \\
\hline 2 semestres & 1 & 7,1 \\
\hline 3 semestres & 2 & 14,3 \\
\hline 4 ou mais semestres & 6 & 42,9 \\
\hline N.S./N.R & 1 & 7,1 \\
\hline \multicolumn{3}{|l|}{ Experiência anterior como tutor: } \\
\hline Não & 11 & 78,6 \\
\hline Sim & 1 & 7,1 \\
\hline Sim, já trabalho como tutor & 2 & 14,3 \\
\hline
\end{tabular}


processo de ensino-aprendizagem no ensino superior. Nesse sentido, atendendo às recomendações do Reuni e ratificando a proposta da universidade, o curso promovido pelo GIZ proporciona uma formação inicial em docência no ensino superior, de maneira semipresencial (abordando temas inerentes à prática docente, como avaliação, planejamento, teorias de aprendizagem e identidade docente universitária), aos mestrandos e doutorandos de todas as áreas do conhecimento, tanto aos que atuam como tutores, quanto aos que se inscrevem como cursistas. ${ }^{3}$ A formação é ofertada em 60 horas ( 20 horas presenciais e 40 horas on-line) e dura quatro meses, possibilitando significativa contribuição a um público que, em muitos casos, não possui formação em Educação nem experiência em sala de aula.

A equipe é composta majoritariamente por pedagogos, que, na ocasião, totalizavam oito. Como o GIZ valoriza a interdisciplinaridade, a equipe não se restringe ao curso de Pedagogia. As diferentes áreas de formação da equipe tendem a ampliar as possibilidades de identificação com o trabalho de Tutoria, o que é parcialmente proporcionado também pela Sala de Tutores, onde é possível trocar experiências, tirar dúvidas e divulgar trabalhos de outras áreas. Essa característica multidisciplinar é inerente à educação a distância, na medida

\footnotetext{
${ }^{3}$ A UFMG, em sua proposta de adesão ao Reuni, como forma de atender à integração entre a graduação e a pós-graduação, propõe a criação de equipes didáticas compostas por docentes e bolsistas de pós-graduação (mestrado, doutorado e pós-doutorado) também como estratégia para o desenvolvimento de novas metodologias e o desenvolvimento da educação no ensino superior. As atividades de professores e bolsistas seriam diferenciadas, podendo estes dedicarse a atividades de ensino até 8 horas/aula por semana.
} 
em que ela exige o envolvimento de diversos profissionais, devido à própria complexidade do trabalho, desenvolvido entre tutores e designers instrucionais. ${ }^{4}$

Ainda em relação ao perfil da equipe, destacamos o tempo de participação nas atividades do programa. O caráter múltiplo da equipe está relacionado também com o tempo institucional de vigência de bolsas e de formação nos programas de mestrado e doutorado, o que exige renovação, flexibilidade e formação constantes entre os membros da equipe. Entre os tutores que participam há mais tempo das atividades de Tutoria (4 semestres ou mais), um é servidor da UFMG, dois estão no programa de doutorado e três estão vinculados ao mestrado. Cada tutor, enquanto estudante de pós-graduação, deve receber uma bolsa de apoio financeiro para se dedicar aos estudos e a atividades de ensino na Universidade, que devem ser de, no máximo, 8 horas/aula semanais. Dessa forma, a equipe de tutores acompanha os cursistas e desenvolve as demais atividades virtuais durante 4 horas/aula por semana, enquanto as outras 4 horas/aula restantes destinam-se aos encontros presenciais - organizados entre as reuniões semanais da equipe e as atividades da formação.

\footnotetext{
${ }^{4} \mathrm{Na}$ educação on-line, o design instrucional se dedica a planejar, preparar, projetar e produzir materiais audiovisuais (textos, imagens, gráficos, atividades e tarefas) ancorados em suportes virtuais, de forma a projetar soluções para problemas educacionais específicos. Ele é responsável por desenhar, implementar e avaliar uma solução para esses problemas. Conferir FILATRO, 2008; FILATRO; PICONEZ, 2004.
} 


\section{AS PERCEPÇÕES DOS TUTORES SOBRE ATIVIDADES DA SALA DE TUTORES}

Como já mencionado, a Sala de Tutores foi pensada e elaborada com o intuito de favorecer a interatividade e a produtividade da equipe de forma ampliada, além de centralizar e facilitar a comunicação, proporcionando também melhor proveito da tecnologia disponível para os cursos. Para captar a percepção dos tutores em relação ao papel que ela ocupa no desenvolvimento do trabalho, foram realizadas algumas perguntas que se encontra sintetizadas na Tabela 2.

Tabela 2 - Percepção dos tutores sobre a Sala

\begin{tabular}{lcc}
\hline \multicolumn{1}{c}{ Percepção } & $\mathbf{N}=\mathbf{1 4}$ Tutores & \% \\
\hline Atribuições da Sala de Tutores*: & 12 & 85,7 \\
Espaço de troca & 8 & 57,1 \\
Lugar de encontros & 13 & 92,9 \\
Espaço de informação & 12 & 85,7 \\
Espaço de formação & 4 & 28,6 \\
Sala de professores & & \\
\hline Relevância da Sala de Tutores: & 13 & 92,9 \\
Muito relevante & 1 & 7,1 \\
Relevante & 0 & 0 \\
Moderadamente relevante & 0 & 0 \\
Pouco relevante & 0 & 0 \\
\hline Não relevante & &
\end{tabular}

(Continua) 


\begin{tabular}{|c|c|c|}
\hline Percepção & $\mathrm{N}=14$ Tutores & $\%$ \\
\hline \multicolumn{3}{|c|}{ Contribuição da Sala de Tutores no } \\
\hline seu trabalho: & 12 & 85,7 \\
\hline Contribui muito & 2 & 14,3 \\
\hline Contribui & 0 & 0 \\
\hline Contribui moderadamente & 0 & 0 \\
\hline Pouco contribui & 0 & 0 \\
\hline \multicolumn{3}{|l|}{ Não contribui } \\
\hline \multicolumn{3}{|c|}{ Sala de Tutores possibilita uma } \\
\hline formação em Tutoria: & 7 & 50,0 \\
\hline Sim, totalmente & 6 & 42,9 \\
\hline Sim, parcialmente & 1 & 7,1 \\
\hline Sim & 0 & 0 \\
\hline Não & 0 & 0 \\
\hline \multicolumn{3}{|l|}{ Não totalmente } \\
\hline \multicolumn{3}{|c|}{ Sentiu-se motivado para desenvolver } \\
\hline \multicolumn{3}{|c|}{ a Tutoria a partir da sua participação } \\
\hline na Sala de Tutores & 10 & 71,4 \\
\hline Sim, totalmente & 2 & 14,3 \\
\hline Sim, parcialmente & 1 & 7,1 \\
\hline Sim & 1 & 7,1 \\
\hline Não & 0 & 0 \\
\hline Não totalmente & & \\
\hline
\end{tabular}

* Nesta questão, poderia ser marcada mais de uma resposta. 
Analisando a opinião dos próprios tutores em relação à relevância dessa sala para o trabalho, observamos que para 13 tutores eła foi considerada "muito relevante" e para um, "relevante", o que representa consenso na percepção desse espaço como referência indispensável para tutores.

Ao manter a Sala de Tutores como um espaço democrático e aberto, fomenta-se a formação da equipe em serviço, pois é possível recorrer a qualquer momento a esse ambiente para tirar dúvidas e aprender, o que leva também à atribuição de "espaço de informação" e à de "espaço de troca". Os registros vão além de um diário ou agenda, pois, ao apresentar as atas de reuniões e as próximas atividades da equipe, configuramse também como uma estratégia didática que favorece a troca de recursos entre os tutores. Como o trabalho de formação na equipe proporciona a formação de duplas ou trios entre os pós-graduandos (um tutor mais experiente, um menos experiente e/ou um novato), é possível, por exemplo, verificar como as diferentes duplas ou trios de Tutoria mediam certas atividades, ou preparam encontros presenciais. Já a atribuição "lugar de encontro" provavelmente diz respeito às possibilidades relativas ao contato contínuo com os membros da equipe - tendo em vista que a equipe se reúne apenas uma vez por semana - e também em função do fórum "Hora do Intervalo", dedicado a tratar de assuntos que não interferem diretamente no trabalho de Tutoria. Em ambos os casos, as interações tendem a favorecer a criação de uma identidade coletiva e reforçar os laços entre os membros, melhorando o trabalho em equipe. 


\section{AS ATIVIDADES DE FORMAÇÃO NA SALA DE TUTORES}

Em relação aos papéis da Sala de Tutores na formação da equipe de Tutoria, foi solicitado à equipe que escolhesse, entre diversas opções, quais as que mais se adequavam às principais atribuições que davam ao espaço do AV. Os resultados estão apresentados na Tabela 3.

Tabela 3 - Percepção dos tutores sobre diferentes atividade de formação desenvolvidas na Sala de Tutores

\begin{tabular}{lcc}
\hline \multicolumn{1}{c}{ Atividades } & $\mathbf{N}=\mathbf{1 4}$ Tutores & $\%$ \\
\hline $\begin{array}{l}\text { Sala de Tutores possibilita a } \\
\text { realização de quais atividades*: }\end{array}$ & & \\
Trabalho em grupo & & \\
$\begin{array}{l}\text { Planejamento das atividades } \\
\text { discutidas presencialmente }\end{array}$ & 10 & 71,4 \\
$\begin{array}{l}\text { Planejamento das atividades } \\
\text { on-line }\end{array}$ & 14 & 100,0 \\
$\begin{array}{l}\text { Organização do grupo, da } \\
\text { equipe e das turmas }\end{array}$ & 14 & 100,0 \\
$\begin{array}{l}\text { Discussão dos temas abordados } \\
\text { na formação }\end{array}$ & 12 & 85,7 \\
$\begin{array}{l}\text { Formas de avaliação } \\
\text { Interação social com colegas de }\end{array}$ & 8 & 57,1 \\
equipe & 11 & 28,6 \\
Resolução de dúvidas sobre a & 10 & 78,6 \\
atuação da Tutoria & 2 & 71,4 \\
Outros & & 14,3 \\
\hline
\end{tabular}

(Continua) 


\begin{tabular}{|c|c|c|}
\hline Atividades & $\mathrm{N}=14$ Tutores & $\%$ \\
\hline $\begin{array}{l}\text { Você recorre a Sala de Tutores } \\
\text { para: }\end{array}$ & & \\
\hline Socialização de experiências & & \\
\hline Troca de materiais & 9 & 64,3 \\
\hline $\begin{array}{l}\text { Acompanhamento e atualização } \\
\text { das atividades }\end{array}$ & $\begin{array}{l}12 \\
13\end{array}$ & $85,792,6$ \\
\hline $\begin{array}{l}\text { Manter-se informado(a) sobre } \\
\text { as reuniões }\end{array}$ & $\begin{array}{l}12 \\
6\end{array}$ & $\begin{array}{l}85,7 \\
42,9\end{array}$ \\
\hline $\begin{array}{l}\text { Socialização de informações } \\
\text { culturais, acadêmicas e outras }\end{array}$ & & 92,6 \\
\hline $\begin{array}{l}\text { Acesso a recursos didáticos e } \\
\text { audiovisuais }\end{array}$ & $\begin{array}{l}13 \\
13\end{array}$ & 92,6 \\
\hline $\begin{array}{l}\text { Acesso a referências } \\
\text { bibliográficas }\end{array}$ & & \\
\hline $\begin{array}{l}\text { Como avalia a formação de } \\
\text { tutores via AV: }\end{array}$ & 12 & 85,7 \\
\hline Totalmente satisfeito & 2 & 14,3 \\
\hline Muito satisfeito & 0 & 0 \\
\hline Satisfeito & 0 & 0 \\
\hline Pouco contribui & 0 & 0 \\
\hline Não contribui & & \\
\hline
\end{tabular}




\begin{tabular}{lcc}
\hline \multicolumn{1}{c}{ Atividades } & $\mathbf{N}=\mathbf{1 4}$ Tutores & $\%$ \\
\hline $\begin{array}{l}\text { Sala de Tutores possibilita uma } \\
\text { formação em Tutoria: }\end{array}$ & 7 & 50,0 \\
Sim, totalmente & 6 & 42,9 \\
Sim, parcialmente & 1 & 7,1 \\
Sim & 0 & 0 \\
Não & 0 & 0 \\
Não totalmente & & \\
\hline
\end{tabular}

*Nesta questão, podia ser marcada mais de uma resposta.

Com base no que está apresentado na Tabela 3, observa-se que existe uma perspectiva relativa ao papel de formação exercido pela Sala de Tutores. Pode-se perceber que essa atribuição está relacionada, principalmente, com as atividades iniciais dos novos bolsistas. Deriva daí a importância de um espaço de formação no qual o tutor possa expressar suas dúvidas e demandas de formação, ao mesmo tempo que atua como espaço de aprendizagem, interação e colaboração da equipe de Tutoria.

Nesse sentido, entre os aspectos marcantes da Sala de Tutoria, a formação dos novos integrantes da equipe assume papel primordial. Como vimos na Tabela 1, de um total de 14 membros, 11 não possuíam experiência como tutores anteriormente ao curso de formação. De acordo com a Tabela 2, 13 afirmam a viabilização da formação em Tutoria por esse espaço e, ainda, 10, conforme Tabela 3, utilizam-no para esclarecer dúvidas 
sobre o trabalho. Em outra análise, na Tabela 2, vimos que todos os 14 membros concordam que há uma significativa contribuição da Sala de Tutores para a realização do trabalho. É importante reconhecermos que o processo de ambientação, sempre necessário aos cursistas, é importante, sobretudo para quem inicia a função na equipe. Além de garantir a continuidade dos valores que norteiam o trabalho exercido especialmente pelo GIZ (como a colaboração e a valorização das pessoas), a imersão no trabalho em um ambiente próprio a sua realização - a plataforma virtual - propicia um reconhecimento mais amplo e real das demandas e desdobramentos que o trabalho de tutor exige. Como podemos perceber na Tabela 3, a equipe recorre constantemente à Sala de Tutores para acessar recursos didáticos e audiovisuais e para discutir os temas abordados na formação, ou seja, esse ambiente permite uma formação em serviço da equipe, que desenvolve, paralelamente à execução do trabalho, competências e habilidades pedagógicas e tecnológicas.

\section{CONSIDERAÇÕES FINAIS}

Diante de todas as mudanças e diferenciações no papel e na conceituação do tutor ao longo do tempo, é evidente a importância da Tutoria virtual nos dias de hoje. Devido ao avanço tecnológico, as mudanças educacionais e a expansão nacional do Ensino Superior, promovido mais recentemente pelo Reuni, a função do tutor é bastante complexa e imprescindível para o sucesso de uma formação. Desempenhando sua atividade como o representante da instituição junto ao estudante, o tutor assume diferentes "vozes" no ambiente virtual (ABREUE-LIMA; ALVES, 2011), podendo, por vezes, atuar como um 
facilitador conceitual, relacionando os comentários dos estudantes aos conceitos trabalhados nas atividades, e como mediador, analisando os posicionamentos em discussões e debates, conduzindo os alunos a um acordo coletivo. O tutor pode ainda ser um guia reflexivo, explorando as postagens dos estudantes com o objetivo de aprofundar algumas reflexões. Ou, por fim, até mesmo como um contador de histórias, apresentando personagens e enredos, fictícios ou não, para problematizar situações.

O tutor também deve estar muito atento à linguagem utilizada nas interações e procurar desenvolver a sensibilidade para perceber o tom adequado das abordagens ao aprendiz. A postura ética e o respeito nas relações, assim como uma presença constante e motivacional, são fatores importantíssimos para que o tutor consiga desempenhar de fato um acompanhamento dialógico na EaD. Tal postura é fundante para promover a reflexão por parte do aprendiz, fazendo-o perceber, enquanto futuro professor, o quão fundamental é a sua presença, sobretudo virtualmente, no processo de ensino-aprendizagem.

Em razão dessa natureza tão complexa do trabalho do tutor é que se percebe a necessidade de um ambiente próprio de formação desse profissional. Criada internamente como estratégia da equipe do Curso de Formação em Docência no Ensino Superior, a Sala de Tutores tem exercido papel fundamental para o sucesso e registro do trabalho (tal como ele acontece) desde 2012.

Um espaço dedicado à centralização, ao registro do processo de trabalho e à formação da equipe também possibilita o 
desenvolvimento de estratégias colaborativas e comunicativas entre os integrantes. De acordo com a Tabela 3, nove integrantes recorrem à Sala de Tutores para socializar as experiências e 10 afirmam que esse espaço possibilita a realização de atividades em grupo. A flexibilidade, liderança e iniciativa são características importantes para o desempenho como tutor, que, por muitas vezes, depara com situações complexas e delicadas e que exigem rápido posicionamento e atitude.

A cumplicidade entre os membros da equipe também é um fator considerável para o sucesso do trabalho. A Sala de Tutores acelera a integração dos membros e permite a sua contínua comunicação, na medida em que os tutores se encontram presencialmente uma vez por semana, o que possibilita o desenvolvimento da afetividade e a formação de valores, refletindo-se na percepção da importância do acolhimento nas abordagens aos cursistas e de sua constância.

Dessa forma, é inegável a importância do papel determinante da Sala de Tutores para a equipe do curso do GIZ e para a formação de tutores de maneira geral. Com uma formação mais sólida e com competências e habilidades mais bem desenvolvidas para o trabalho, o tutor sente-se mais seguro para atuar. Capaz de dominar bem as ferramentas da EaD (SOUZA, 2004) e desenvolvendo um acompanhamento mais consistente, estimulante e assertivo, o tutor contribui diretamente para o sucesso da proposta educacional. A partir da condução deste trabalho, percebemos como a formação da equipe, composta em sua maioria por pós-graduandos, gera a formação dos cursistas, possíveis integrantes de 
futuras equipes didáticas, seja enquanto estudantes, seja enquanto docentes. Temos, assim, um efeito multiplicador, que corrobora uma das propostas da UFMG em decorrência do Reuni, e em rede, ratificando também uma das filosofias do GIZ: a formação de uma rede de desenvolvimento de práticas de Ensino Superior.

\section{REFERÊNCIAS}

ABREU-E-LIMA, D. M.; ALVES, M. N. O feedback e sua importância no processo de tutoria a distância. ProPosições, Campinas, v. 22, n. 2 (65), p. 189-205, maio-ago. 2011.

BEZERRA, M. A.; CARVALHO, A. B. G. Tutoria: concepções e práticas na educação a distância. In: SOUSA, R. P.; MIOTA, F. M. C. S. C.; CARVALHO, A. B. G. (Org.). Tecnologias digitais na educação [online]. Campina Grande: EDUEPB, 2011. Disponível em: <http://books.scielo.org>. Acesso em: 15 ago. 2014.

BRASIL. Decreto 6.096 de 24 de abril de 2007. Institui o Programa de Apoio ao Plano de Reestruturação e Expansão das Universidades Federais - REUNI. Brasília: MEC, 2007a.

BRASIL. Ministério da Educação. Secretaria de Educação a Distância. Referenciais de Qualidade para a Educação Superior a Distância. Brasília: MEC, 2007b.

BRASIL. Ministério da Educação. Secretaria de Educação a Distância. REUNI, Reestruturação e Expansão das Universidades Federais: Diretrizes gerais. 2007c. Disponível em: <http://portal.mec.gov.br/sesu/arquivos/ pdf/diretrizesreuni.pdf>. Acesso em 26 de jul. 2014. 
DUARTE, E. C. V. G.; POLAK, Y. N. S. O tutor de sala como eixo articulador da aprendizagem. In: CONGRESSO INTERNACIONAL DE EDUCAÇÃO À DISTÂNCIA, 13., 2007, Curitiba. Anais... Curitiba: Abed, 2007.

FILATRO, A. Design instrucional na prática. São Paulo: Pearson Education do Brasil, 2008.

FILATRO, A.; PICONEZ, S. C. B. Design instrucional contextualizado. In: CONGRESSO INTERNACIONAL DE EDUCAÇÃO A DISTÂNCIA, 11., 2004, Salvador. Anais ...Disponível em: <http://www.abed.org.br/ congresso2004/por/htm /049-TC-B2.htm>. Acesso em: 1 ago. 2014.

GARCÍA ARETIO, L. Educación a distancia hoy. Madrid: UNED, 1994.

IAHN, L.F. Concepções políticas em educação a distância. In: POLAK, Y. N. S. A construção do percurso em educação a distância: formação de tutores. Curitiba: Editora Própria, 2002.

MILL, D. Educação a distância e trabalho docente virtual: sobre tecnologia, espaços, tempos, gênero e coletividade na Idade Mídia. 2006. 248p. Tese (Doutorado em Educação) - Faculdade de Educação, Universidade Federal de Minas Gerais, Belo Horizonte, 2006.

MIZUKAMI, M. G. N. Ensino-aprendizagem: as abordagens do processo. São Paulo: EPU, 1985.

MOORE, M. G; KEARSKEY, G. Educação a distância: uma visão integrada. Trad. Roberto Galman. São Paulo: Cengage Learning, 2008.

OLIVEIRA, M. R. G. O. ; MILL, D. ; RIBEIRO, L. R. C. A Gestão da sala de aula virtual e os novos saberes para a docência 
na modalidade de educação a distância. In: COLÓQUIO INTERNACIONAL SOBRE GESTÃO UNIVERSITÁRIA DA AMÉRICA DO SUL, 9., 2009, Florianópolis. Anais... Florianópolis: Abed, 2009. Disponível em: <http://www. abed.org.br/congresso2007/> Acesso em: 7 jun. 2014.

PRETI, O. O estado da arte sobre "Tutoria": modelos e teoria em construção. Capítulo 1 do Relatório de Pesquisa O sistema de Orientação Acadêmica no curso de Pedagogia a distância da Universidade Federal de Mato Grosso, 2003. Disponível em: <http://www.uab.ufmt.br/ uab/images/artigos_site_uab/tutoria <estado_arte.pdf>. Acesso em: 18 jun. 2014.

PRIMO, A. F. T. Ferramentas de interação em ambientes educacionais mediados por computador. Educação, v. XXIV, n. 44, p. 127-149, 2001.

SOUZA, M. G. A arte da sedução pedagógica na tutoria em educação a distância. Brasília: MEC-SEED-Proinfo, 2004. 


\section{ABSTRACT}

This paper describes the continuing tutoring training in the experience of distance education implemented in the University of Minas Gerais through GIZ/Prograd. Within the context of Reuni, GIZ has implemented the Undergraduation Teaching Training. Offered to UFMG Master and PhD students. FDES has a team mostly composed by graduate students in Education, and GIZ staff. The training takes place in a space of virtual interaction - Tutor Room - in which the didactic and pedagogical strategies are discussed before being implemented. The challenges in setting effective pedagogical dynamics from the theoretical, methodological and technological training aspects, focus of this analysis, have been systematically discussed and developed in this space, while the theoretical and practical training of these individuals happened. These results lead us to reflect on the pedagogical potential of distance learning for those who will work with tutoring in distance education.

Keywords: Distance education. Tutoring. Continuing training. Tutor room. Undergraduation teaching. 
